International Journal of Engineering \& Technology, $7(3.36)(2018) 23-33$
International Journal of Engineering \& Technology
SPC
Website: www.sciencepubco.com/index.php/IJET
Research paper

\title{
A Comparative Study between Three-Legged and Tripod Sub-structures in Design of Offshore Wind Turbines in the Transition Water Depth
}

\author{
Aliakbar Khosravi, Tuck Wai Yeong*, Mohammed Parvez Anwar, Jayaprakash Jaganathana, Teck Leong Lau, \\ Wael Elleithy
}

Department of Civil Engineering, The University of Nottingham Malaysia Campus, 43500 Semenyih, Selangor, Malaysia

*Corresponding author E-mail: tuck-wai.yeong@nottingham.edu.my

\begin{abstract}
This research aimed at investigating tripod and three-legged offshore wind turbine substructures. A comparison between the two substructures based on their weight as well as the installation method of piles, i.e. pre-piling and post-piling, was carried out. The in-place (Ultimate Limit State), Dynamic, natural frequency check and fatigue (Fatigue Limit State) analyses were conducted considering aerodynamic and hydrodynamic loads imposed on substructures in 50m water depth. An optimisation process was carried out in order to reduce the mass of substructures. The results revealed that the three-legged substructure is more cost effective with $25 \%$ lesser structure mass. However, the construction of the three-legged structure usually takes more time due to increased number of members and subsequently welding joints. The results, furthermore, showed that the pre-piling method reduces the time and cost of offshore installation, and reduces the weight of piles by $50 \%$.
\end{abstract}

Keywords: Installation method; substructure; three-legged, tripod; wind turbines.

\section{Introduction}

Due to oil shortage and climate change, scientists are currently putting more emphasis on alternative energy sources, particularly wind energy which plays an effective role to produce green energy. Offshore wind energy has become a hot topic in the renewable energy industry recently, see e.g. references [1-19] and the references cited therein, not to mention many others.. Ample of projects were deployed in shallow water under $30 \mathrm{~m}$ water depth and further research is required to make offshore wind turbines (OWT) more cost-effective for deeper water depths. The cost of an offshore wind turbine is higher than onshore one due to its heavier weight, and the higher expenses associated with its installation and transportation. Hence, design of lighter offshore substructure would affect project cost significantly.

Different types of wind turbine substructures can be selected based on water depth, dynamic loads, seabed soil properties and the cost/availability of transportation vessel and lifting crane. Jonkman [5] classified water depth into three categories. The study considered $0-30 \mathrm{~m}$ as shallow water that is suitable for monopoles and gravity foundation, $30-60 \mathrm{~m}$ as transitional water, which is suitable for tripods, jackets and truss-type towers and greater than $60 \mathrm{~m}$ as deep water, which may require floating structures.

According to Kolios et al. [6], the fixed substructures can be categorised based on structural configuration. The Gravity-based and gravity pile substructures are solid-based structures which are more suitable up to $25 \mathrm{~m}$ water depth. The Lattice and jacket are built up of three or more legs connected by tubular braces and are suitable for $20-40 \mathrm{~m}$ and $25-50 \mathrm{~m}$ water depths, respectively. The tripod substructure is a lightweight three-leg structure made of a central steel column and a steel frame near the seabed consisting of three diagonal braces. The braces transfer loads from the column to the three piles. The soil conditions have an impact on the steel frame's dimensions. Its foundation can be suction bucket anchors or pile skirt. The advantage of the suction bucket is that pile driving is not required for installation. Typical sites should allow the use of suction anchors and not be prone to scour, but piling has the advantage of requiring less protection against scour. The tripod substructure is usually suitable for water depths between $25-50 \mathrm{~m}$. The monopile substructure is a simple design comprising a column that extends into the seabed. It is an advantageous system in areas with soft seabed, but its drawback is its high flexibility in deep waters. This limits its water depth up to $25 \mathrm{~m}$.

Ashish and Panneer Selvam [7] recommended the use of fixed offshore wind turbine substructures in deep water where winds are more powerful. Reliable substructures such as jacket and gravity base can withstand the meta-ocean loads as well as dynamic loads from the wind turbine compared to floating structures. The wave and current loads increase dramatically in deep waters. Hence, a fixed offshore structure can provide adequate strength capacity. Preliminary proposed concepts utilise designs borrowed from the oil and gas industry developed much earlier than offshore wind structures. Chew et al. [8] compared three-legged and four-legged jacket types and concluded that the former could save around $13 \%$ of structural weight while gaining a $25 \%$ reduction in the number of joints.

This study aimed at investigating the structural behaviour/response of three-legged and tripod substructures of offshore wind turbines considering all imposed loads during the lifetime in a transition water depth, e.g., $50 \mathrm{~m}$ water depth in the 
Persian Gulf. A comparison between the two substructures based on the weight of substructures as well as the installation method of piles was carried out.

\section{Methodology}

\subsection{Water depth and site location}

In the Persian Gulf, the overall water depths are shallow. The average and maximum water depths are about $50 \mathrm{~m}$ and $90 \mathrm{~m}$, respectively. For this study, a reference location, i.e., the Reshadat Field was chosen. The field is located in the Persian Gulf, $110 \mathrm{~km}$ south-west of Lavan Island, as shown in Figure 1, with an average water depth of $50 \mathrm{~m}$. It should be noted that, the three-legged and tripod substructures are feasible for multiple locations with similar environmental loads. Wave sensitivity studies were performed to select the water depths and wave critical positions between minimum and maximum water depths.

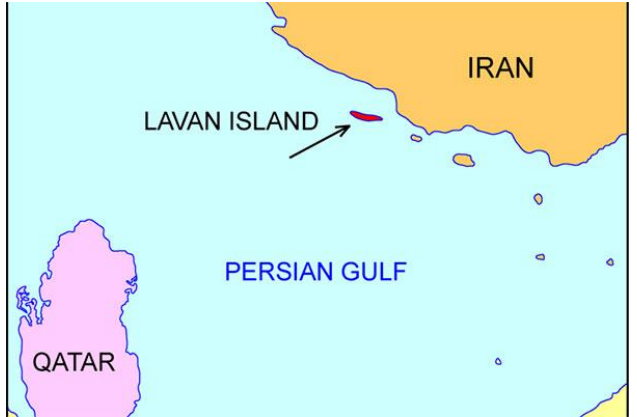

Fig. 1: Reshadat Filed in the Persian Gulf [9].

\subsection{Wind turbine selection}

The wind turbine selected for this study is 5-MW standard OWT The critical turbine parameters are shown in Table 1 [5].

Table 1: Main parameters of the 5-MW wind turbine [5]

\begin{tabular}{lc}
\hline Parameter & Value \\
\hline Rated power [mw] & 5 \\
Rotor diameter [m] & 126 \\
Minimum rotor speed [rpm] & 6.9 \\
Rated rotor speed [rpm] & 12.1 \\
Rotor mass [tonne] & 110 \\
Nacelle mass [tonne] & 240 \\
\hline
\end{tabular}

\subsection{Pile installation methods}

The foundation of a substructure plays a major role in the design of wind turbine substructures and the method of installation has an impact on the analysis results. Pre-piling and post-piling installation methods were considered in this study.

\subsection{Software}

SACS is a commercial software package that can explore design alternatives for safe, cost-effective offshore wind farm structures [20]. SACS has been utilised in some parts of this study.

\subsection{Analysis and design}

The three-legged substructure, shown in Figure 2a, consists of three battered legs with six horizontal elevations and Z-type diagonal braces. Cans were used in joint connections to avoid over stress due to punching shear and fatigue life of substructure. The tripod substructure consists of a central tubular column and a steel frame near the seabed which includes six diagonal braces and a horizontal elevation frame. The braces transfer loads from column to the three piles (Figure 2b).
Several design configurations/dimensions of the three-legged and tripod substructures were determined for the best arrangement of structural elements and foundations.

The structural model consists of all structural members, the pile foundations and a simplified model of the wind turbine's structural members. The wind turbine tower was modelled to consider the effect of wind and weight as well as stiffness on the substructure. The tower is connected to transit piece with dimension of $5.7 \mathrm{~m}$ diameter, $50 \mathrm{~mm}$ thickness, and a $75 \mathrm{~mm}$ grout between transition piece and tower. The effects of the un-modelled elements are accounted for by modifying the hydrodynamic coefficients.

The piles inside the substructure or the skirt piles are modelled using elements with equivalent axial and bending stiffness properties. The foundations are represented by a series of elements constrained by vertical and lateral linear spring elements representing the non-linear pile/soil behaviour. The pile foundation was modelled as part of a structured system using non-linear soil $\mathrm{p}-\mathrm{y}, \mathrm{t}-\mathrm{z}$ and $\mathrm{Q}-\mathrm{z}$ curves which are generated from site-specific data. The effects of global seafloor scour, local scour in granular soils and the partial loss of soil-pile contact in cohesive soils was accounted for.

The pre-piling and post-piling of the foundation were investigated for three-legged and tripod substructures in order to observe the effect of piles while placed inside the legs (post-piling) or leg without internal pile (pre-piling) connected to pilecap.

The piles and legs were modelled as different members in the SACS model. In the three-legged planes, El. (+)8.00, (+)4.2, ()5.2, (-)18.2, (-)32.7 and (-)50, as shown in Figure 2, are connected with the rigid members which are called wishbone (only for post-piling method). These members are released in global translation in the $\mathrm{Z}$ direction and all three rotational freedoms. The top of substructures legs and piles are connected by introducing the common joint. For the second type of post-piling, the gap between leg and pile is filled with grout.

The members of structures were designed to withstand aerodynamic and hydrodynamic loads. Since the target is to compare those structures considering mass and installation methods, the unity check ratio member (actual combined stress over allowable stress) must be limited between $0.8-1.0$, in order to ensure that the design is optimised. However, the design of offshore wind turbines is not only about unity check of in-place analysis, the designer should also consider other criteria such as the deflection of substructures, punching shear check, natural frequency check and fatigue life which have important roles in the design of the substructure.

The flowchart in Figure 3 shows seven different analyses types that were performed to design the offshore wind turbine substructures with the main ones being in-place, dynamic and natural frequency check, and fatigue and earthquake which is known as inservice analysis. Since the Persian Gulf is located in a low earthquake risk area, the earthquake analysis will not have any effect on structural members

It should be highlighted that the load-out, installation and transportation analyses (also known as pre-service) are not part of this study as they are analysed based on the method of installation and type of vessel.

The analysis types/methods and design drivers/loads/data, considered in this study, for three-legged and tripod OWT substructures are presented in detail in Sections 3 and 4 , respectively. 


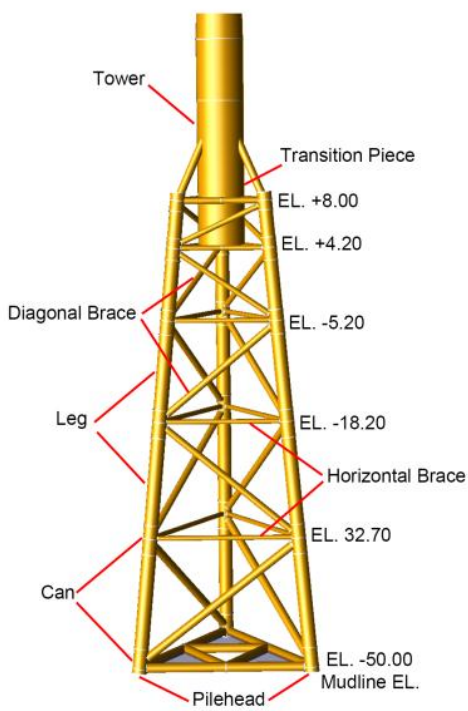

(a)

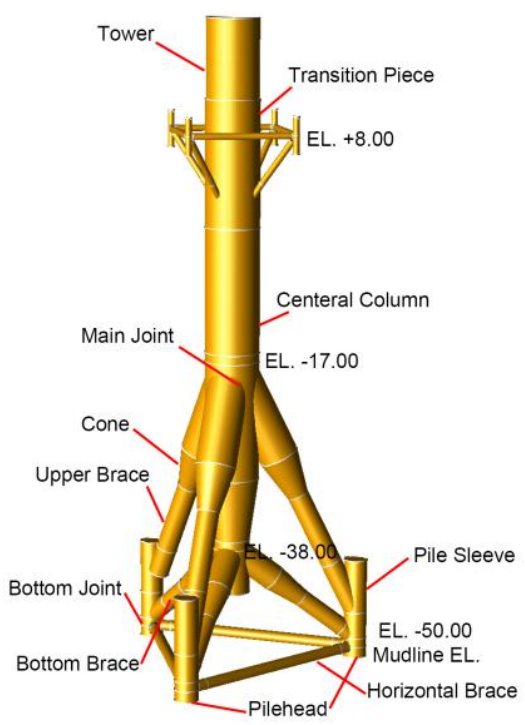

(b)

Fig. 2: (a) Three-legged and (b) Tripod general arrangements.

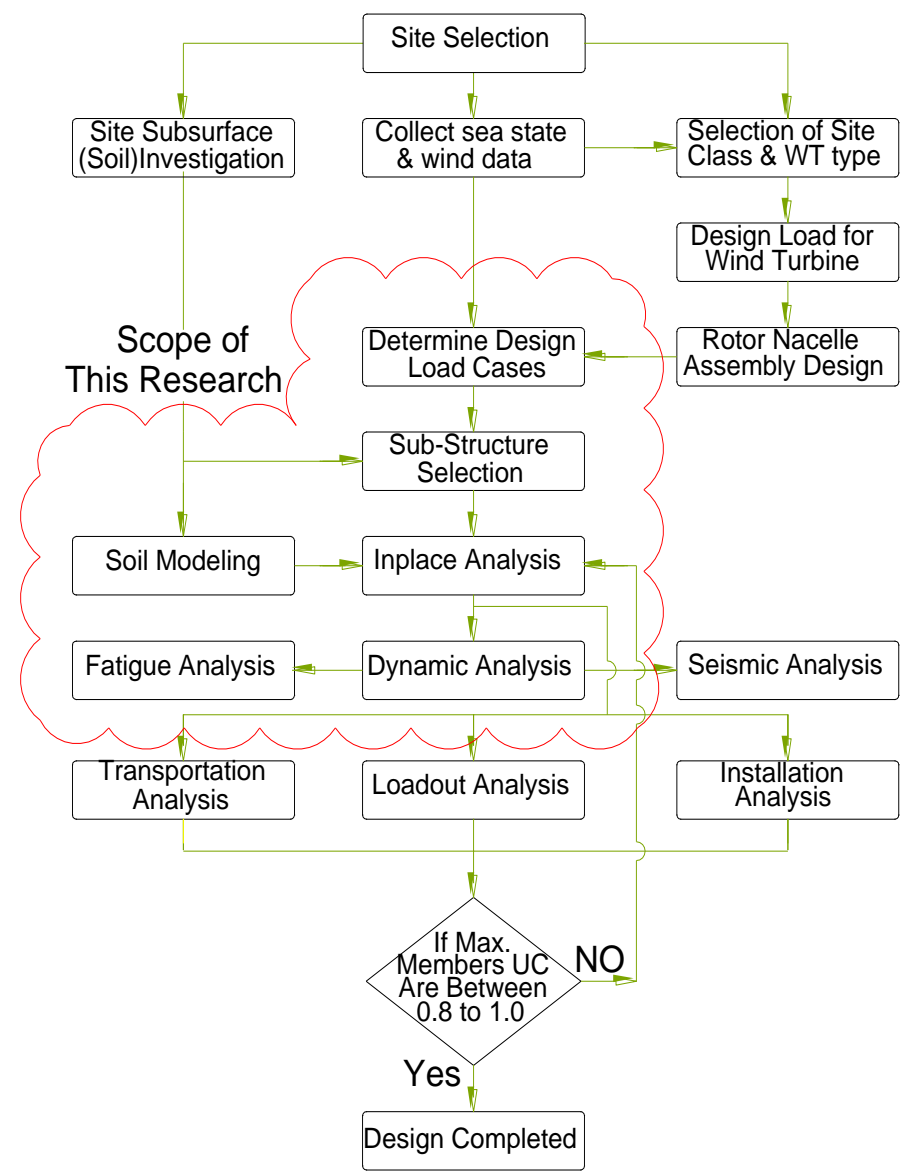

Fig. 3: Design Process for Offshore Wind Turbines.

\section{Analysis}

The analysis types/methods considered in this study, for threelegged and tripod OWT substructures are presented in what follow.

\subsection{Static in-place analysis}

The in-place analysis procedure is based on a linear elastic response of the structure under static loading conditions. The soil non-linearity has been considered by using the load deflection data $(\mathrm{P}-\mathrm{y}, \mathrm{T}-\mathrm{z}$, and $\mathrm{Q}-\mathrm{z})$ in line with soil data.

\subsection{Dynamic analysis and natural frequency check}

The dynamic behaviour of the substructure is an important design driver for offshore wind turbines. Most of the environmental loads are dependent on time and time scale is closed with the resonant period of the structure. Hence, a dynamic analysis is required. 
De Vries [10] clarified that the natural frequency is an important feature and an analysis is required to determine the dynamic behaviour of OWT. The natural frequencies of the substructure may be compared with the frequencies of any excitations. Hence, in order to avoid resonance vibration, it is important to ensure that the natural frequency of the substructure does not fall into the range of excitation. Otherwise, it causes higher stress ranges in the substructure and has a huge impact on the fatigue life of the offshore wind turbine. Relatively short waves with a significant 1 $\mathrm{m}$ to $1.5 \mathrm{~m}$ wave height $\mathrm{Hs}$ and a zero-crossing period $\mathrm{Tz}$ of $4 \mathrm{~s}$ to $5 \mathrm{~s}$ have the largest effect due to their frequent occurrence.

Since the National Renewable Energy Laboratory (NREL) 5MW turbine is considered for this study, the operation of the rotor causes harmonic excitation, and the rotor's rotational frequency is $1 \mathrm{P}$ and blade passing frequency, is usually taken as $3 \mathrm{P}$. Therefore, for the substructure design, the first natural frequency interval (for lower boundary) should remain between $0.222 \mathrm{~Hz}$ to $0.311 \mathrm{~Hz}$ (the interval is shown $1 \mathrm{P}$ ) and the upper boundary of $3 \mathrm{P}$ range natural frequency should remain more than $0.666 \mathrm{~Hz}$ to avoid resonance.
The natural frequency of dynamic system properties is determined by mass distribution and equivalent stiffness. The turbine manufacturer recommends that an additional safety factor of $10 \%$ should be considered for the lower and upper boundary. The forcing frequencies plotted versus the power spectral densities are presented in Figure 4.

The equations of motion for an undamped free vibrating system can be written as [3]

$[\mathrm{M}] \ddot{\mathrm{x}}+[\mathrm{K}] \mathrm{x}=0$,

where, $[\mathrm{M}]$ and $[\mathrm{K}]$ are the mass and stiffness matrices, respectively. Assuming the displacement vector as $\mathrm{x}=\mathrm{A} \sin \omega \mathrm{t}$, the equation of motion becomes

$\left(-\omega^{2}[\mathrm{M}]+[\mathrm{K}]\right) \mathrm{x}=0$.

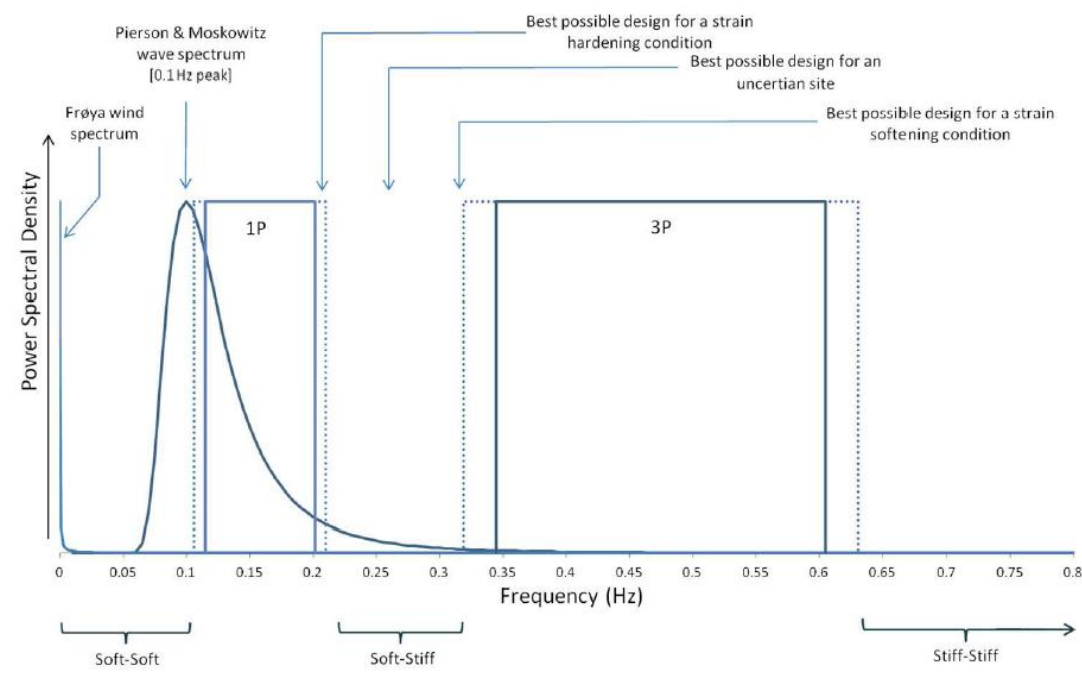

Fig. 4: Forcing frequencies plotted vs. power spectral densities [11]

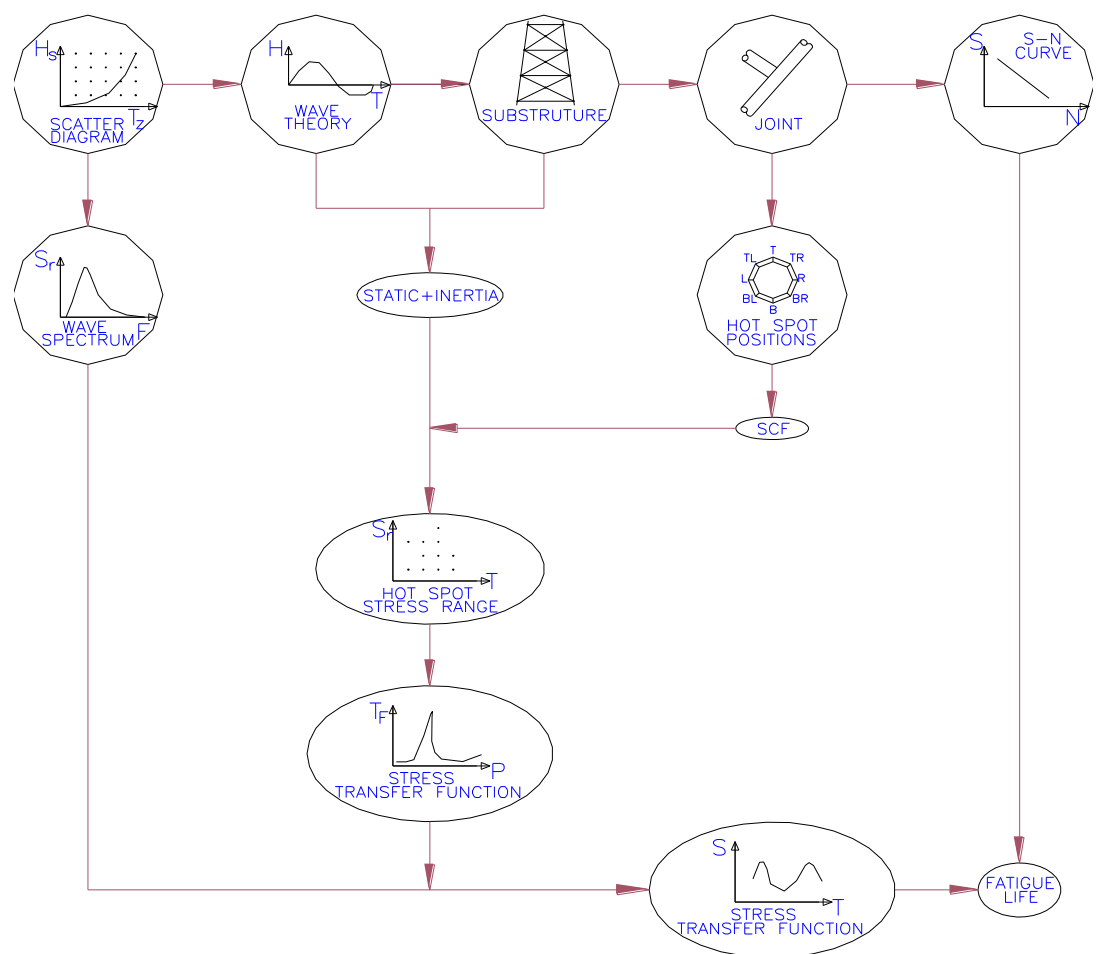

Fig. 5: Spectral dynamic fatigue analysis scheme [9] 


\subsection{Fatigue analysis}

One of the key issues in offshore structure analysis is the response of the structure to wave loading [12]. The waves produce dynamic effects that tend to increase the stresses and influence the longterm behaviour of the structure. In offshore structures, fatigue effects need to be investigated in the certain hot spot and can only be properly analysed using dynamic theory. The interaction effects of foundation-structure are dependent on frequency. Design wave height and period are not adequate as they do not represent the variability of the sea states. For the fatigue analysis, a good history prediction with different stress magnitudes and the associated number of cycles are required.

Khalifa et al. [13] presented an analysis procedure for numerical fatigue assessment that is based on S-N curve approach for API RP 2A standard [21,22], utilising the simplified method and the spectral (stochastic) method. Hence, in this study spectral method is considered.

The centre of damage wave is determined based on the significant wave height $(\mathrm{Hs})$ with associated period $(\mathrm{T})$ and the number of wave cycles (n) and usually in eight wave directions. The total fatigue damage due to the whole sea states is approximately equal to the damage calculated under the centre of the damage wave. The damage in particular sea states is proportional to the number of waves it has and how often that sea state occurs. The damage is also commensurate with the height of the waves raised to the power of the S-N curves. Thus for each sea state, by using these relationships, it is possible to calculate a number that is proportional to the damage.

For a field service life of 20 years, the substructure should withstand its functional operation for a minimum of 40 years fatigue design life. Any joints in the splash zone shall have a minimum of 60 years fatigue design life [23].

In this study, the output of the response calculation was taken as the nominal force amplitude for each structural member as a function of frequency. The member end forces (axial, in plane and out of plane bending) were used to generate the stress range transfer functions. Stress concentration factors (SCFs) for simple tubular joints (X, T, Y, K or KT joints) were calculated using parametric formulae [19]. SCFs should not be less than 1.5. The Spectral Dynamic Fatigue Analysis Scheme is shown in Figure 5.

\section{Design}

Figure 6 shows a schematic of the interface level that should be established [10]. For this study, he interface level between substructures and tower is considered at $20.15 \mathrm{~m}$ with regard to the highest crest elevation and air gap.

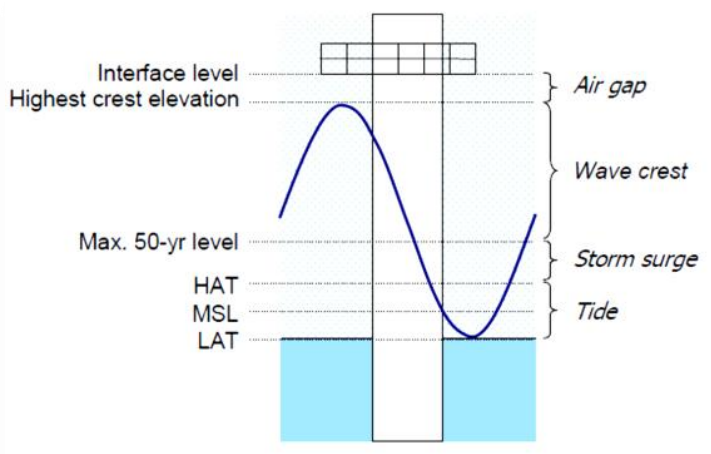

\subsection{Grout}

Grout was used in between pile-to-leg connections where applicable. The weight of grout was considered in the models where the grout connection is used. Also, for connection where grout fills the annulus between the tubular member and piles, the chord thickness can be increased by Equation (3) for fatigue analysis as per DNV [23],

$\mathrm{T}_{\mathrm{e}}=\mathrm{T}+0.45 \mathrm{~T}_{\mathrm{p}}$,

where, $\mathrm{T}_{\mathrm{e}}$ is the equivalent chord wall thickness, $\mathrm{T}$ is the chord thickness and $T_{p}$ is the thickness of the inserted pile.

\subsection{Loading}

For aerodynamic loads, the set of wind loads is taken from [6] as presented in Table 2 . No hydrodynamic effects have been taken into account in the aerodynamic simulations, as these will be calculated in the ULS analysis in SACS.

The load cases in Table 2 show power production situations. The 1.3 cases correspond to extreme turbulence intensity in the wind conditions, whereas the 1.4 cases are concerned with the occurrence of an extreme coherent gust with a change of direction. The hydrostatic loads (wind, wave and current) as well as gravity and bouncy loads were combined with load cases in Table 2 for inplace analysis.

\subsection{Environmental loads}

Wind turbine structures are subjected to environmental loads induced by external environmental parameters such as wind, waves, current, corrosion, earthquakes, temperature, ice, marine growth. Experience has shown that the effects of earthquakes and temperatures are insignificant compared to other environmental loads on substructures in the Persian Gulf, and there is no ice load in that region. For this reason, such loads are not taken into consideration in this study.

Noorzaei et al. [14] suggested that the Airy's linear theory is not suitable for deep water and that Stoke's fifth order theory models the free water surface more precisely creating steeper crests and lower troughs. The fifth order stock's theory increases crests in comparison to Airy's theory and maintains the convective accelerations terms while Airy's theory ignores them.

Morison's and the diffraction methods are the two main methods used for estimating wave loads. The Morison's method which is applicable in time and frequency domain is recommended to be used for slender structures such as monopod, tripod and jacket. The diffraction method which is applicable in the frequency domain is recommended for massive structures such as gravity base supports [15].

The sea state is defined by a statistical distribution, which is an energy density spectrum (EDS). The area under the spectrum graph of a wave is the same for diverse wave spectra. In other words, the total energy is the same for the same sea states.

Fig. 6: Determining the interface level [10].

Table 2: Aerodynamic loads at interface level [10]

\begin{tabular}{llllllll}
\hline & & Load Case & $\mathrm{Mx}[\mathrm{kNm}]$ & $\mathrm{My}[\mathrm{kNm}]$ & $\mathrm{Mz}[\mathrm{kNm}]$ & $\mathrm{Fx}[\mathrm{kN}]$ & $\mathrm{Fy}[\mathrm{kN}]$ \\
\hline $\mathrm{Mx}$ & Max & $1.3 \mathrm{ec} \_1$ & 21067 & 24935 & -601.7 & 396.3 & -175 \\
$\mathrm{Mx}$ & Min & $1.3 \mathrm{ea} \_2$ & -7293.9 & 9281.1 & -2235.2 & 316.2 & 115.9
\end{tabular}




\begin{tabular}{|c|c|c|c|c|c|c|c|c|}
\hline My & Max & 1.3ca_3 & 7467.2 & 58379 & 2678.4 & 924.3 & -21 & -5722.4 \\
\hline My & Min & $1.4 \mathrm{aa}$ & 12836 & -5283.1 & 276 & 36.6 & -149.3 & -5671 \\
\hline $\mathrm{Mz}$ & Max & $1.3 e c \_3$ & 10804 & 10907 & 7351.8 & 239.3 & -58.6 & -5887.8 \\
\hline $\mathrm{Mz}$ & Min & 1.3ea_2 & 728.4 & 6838.1 & -11290 & 309.5 & 54 & -5563.3 \\
\hline Fx & Max & 1.3aa_2 & 3158.9 & 50301 & 2140.9 & 972.1 & 20.1 & -5785 \\
\hline Fx & Min & $1.4 \mathrm{aa}$ & 13135 & -4356.7 & 140.8 & 15.5 & -125.8 & -5675.1 \\
\hline Fy & Max & 1.3ea_3 & -1904.7 & 14437 & -2588.9 & 406 & 202.1 & -5684.9 \\
\hline Fy & Min & $1.4 \mathrm{cc}^{-}$ & 18210 & 18072 & 186.1 & 353.4 & -249.8 & -5648.9 \\
\hline $\mathrm{Fz}$ & Max & 1.3ea_3 & 5388.8 & 18015 & -2858.3 & 358.4 & -8.6 & -5367.8 \\
\hline $\mathrm{Fz}$ & Min & $1.3 \mathrm{ec} \_3$ & 8266 & 9548 & 6218.7 & 258.3 & -71.4 & -5921 \\
\hline
\end{tabular}

Chakrabarti [16] categorised several common wave spectrum models derived from experimental data, such as PiersonMoskowitz, Bretschneider, ISSC, JONSWAP and Ochi-Hubble. The two-parameter wave spectrum of Pierson-Moskowitz and JONSWAP are widely used in offshore structures. The PiersonMoskowitz spectrum is defined based on experimental wave data from the North Atlantic Ocean while the JONSWAP spectrum is based on experimental wave data from the North Sea [17].

The Pierson-Moskowitz spectrum is generally used all over the world, and the JONSWAP is used for the North Sea [24]. The Pierson-Moskowitz and JONSWAP spectra are presented as,

$$
\mathrm{S}_{\eta \eta}(\omega)=\alpha \mathrm{g}^{2} \omega^{-5} \exp \left[-\frac{5}{4}\left(\frac{\omega}{\omega_{p}}\right)^{-4}\right] \gamma^{\exp \left[-0.5\left(\frac{\omega-\omega_{p}}{\sigma \omega_{p}}\right)^{2}\right]}
$$

where, $\omega=$ angular wave frequency $=2 \times \pi / \mathrm{T}_{\mathrm{w}} ; \mathrm{T}_{\mathrm{w}}=$ wave period; $\mathrm{T}_{\mathrm{p}}=$ peak period or significant wave height period $\mathrm{T}_{\mathrm{z}} ; \omega_{\mathrm{p}}=$ angular spectral peak frequency $=2 \times \pi / \mathrm{T}_{\mathrm{p}} ; \mathrm{g}=$ gravity acceleration; $\alpha=$ generalised Philip's constant; $\sigma=$ spectral width parameter 0.07 if $\omega<\omega_{\mathrm{p}}$ or 0.09 if $\omega>\omega_{\mathrm{p}}$ and $\mathrm{\gamma}=$ peak parameter; equals to 1.0 for Pierson-Moskowitz spectrum.

Once a structure is located in the wind path, it causes a blockage or deflection of the wind from its path resulting in all or part of the kinetic energy being transferred to the potential energy pressure. The wind forces depend on the direction, wind speed, shape of the structural elements and area. The wind forces are dynamic by nature. However, it can be considered static pressure [18].

The basic relationship between the wind velocity and the wind action on an object is [25],

$\mathrm{F}:=\frac{1}{2} \rho_{\mathrm{a}} \mathrm{U}_{\mathrm{w}}{ }^{2} \mathrm{C}_{\mathrm{s}} \mathrm{A}$,

where, $\mathrm{F}$ is the wind action on the object; $\rho_{\mathrm{a}}$ is the density of air (at standard temperature and pressure); $\mathrm{U}_{\mathrm{w}}$ is the wind speeds, $\mathrm{C}_{\mathrm{s}}$ is the shape coefficient, and $\mathrm{A}$ is the area of the object.

The wind velocity (10 minutes average) is used for the global design of substructures. Basic wind speeds are indicated at $10 \mathrm{~m}$ above Maximum Tide Level. The shape coefficients are used for perpendicular wind approach angles and the values.

\subsubsection{Wave}

The DNV [24] recommends the use of 5 and 50 wave/current years return period for the design of offshore wind turbines substructures (OWTs). For the Reshadat Field in the Persian Gulf, only the 1 year and 100 years return period are available which is suitable for the design of OWTs based on API [21,22]. The DNV [24] is used for interpolation of 5 and 50 years from 1 and 100 years return period (Table 3 ).

\subsubsection{Wind}

The multi-directionality of the wind and the waves may have an important influence in some cases on the loads acting on the support structure, depending primarily on whether the structure is axisymmetric or not. The load combinations calculations were undertaken by assuming that the wind and the waves are acting co-directionally from a single, worst-case direction. The available wind speed is based on the wind on $10 \mathrm{~m}$ above LAT (Table 4). Since the hub height is at elevation $90.55 \mathrm{~m}$, the wind speed shall be converted to hub elevation.

Equation (6) can be used to determine the wind at hub elevation [24],

$$
\mathrm{U}(\mathrm{T}, \mathrm{z})=\mathrm{U}_{10} *\left(1+0.137 \ln \frac{\mathrm{Z}}{\mathrm{h}}-0.047 \ln \frac{\mathrm{T}}{\mathrm{T}_{10}},\right.
$$

where: $\mathrm{h}=10 \mathrm{~m}, \mathrm{~T}_{10}=10$ minutes and $\mathrm{z}=$ required height. The maximum wind speed at hub elevation among eight directions is presented in Table 5

Table 3: Max. wave height/period for 5 and50 years return period

\begin{tabular}{cccc}
\hline Return Period (years) & Hs [m] & Tp [s] & Hmax [m] \\
\hline 5 & 4.9 & 9.6 & 9 \\
50 & 6.3 & 10.7 & 11.7 \\
\hline
\end{tabular}

Table 4: Max. wind speeds for 5 and 50 years return period Return Period (years) $\quad \mathrm{V}_{\mathrm{w}}(10$ min-mean) $[\mathrm{m} / \mathrm{s}]$

\begin{tabular}{cc} 
Return Period (years) & $\mathrm{V}_{\mathrm{w}}(10$ min-mean $)[\mathrm{m} / \mathrm{s}]$ \\
\hline 5 & 23.8 \\
50 & 31.6 \\
\hline
\end{tabular}

Table 5: Max. wind speeds at hub El. for $5 \& 50$ year return period. Return Period (years) Vw(10min-mean) $[\mathrm{m} / \mathrm{s}]$

\begin{tabular}{cc} 
Return Period (years) & $\mathrm{Vw}(10 \mathrm{~min}-\mathrm{mean})[\mathrm{m} / \mathrm{s}]$ \\
\hline 5 & 31 \\
50 & 38.8 \\
\hline
\end{tabular}

\subsubsection{Current}

Current and wind act in the same direction. The maximum current speed among eight directions is presented in Table 6.

Table 6: Max. current speeds for $5 \& 50$ year return period

\begin{tabular}{ccc}
\hline & 5 Year return & 50 Year return \\
\hline Surface $(\mathrm{m} / \mathrm{s})$ & 0.94 & 1.04 \\
Mid Depth $(\mathrm{m} / \mathrm{s})$ & 0.66 & 0.75 \\
$5 \mathrm{~m}$ above seabed $(\mathrm{m} / \mathrm{s})$ & 0.47 & 0.5 \\
$0.5 \mathrm{~m}$ above seabed $(\mathrm{m} / \mathrm{s})$ & 0.4 & 0.4 \\
\hline
\end{tabular}

\subsection{Load combinations}

As there exist two or more environmental load types, the DNV code recommends five load combinations for design [24]. However, there is no ice load in the Persian Gulf; hence ice load will be ignored.

The wave loads have been investigated for multi-directional waves in eight critical environmental incidences, i.e., $15^{\circ}, 60^{\circ}, 105^{\circ}$, $150^{\circ}, 195^{\circ}, 240^{\circ}, 285^{\circ}$ and $330^{\circ}$. Figure 7 presents the direction of the investigated environmental loadings. The current was always modelled acting in the same direction as the relevant wave. Multidirectional current values have been used, and a current blockage factor of 0.9 was utilised.

As this is a case study, the real orientations of the substructures are not known. The directions of wave, wind and current are predicted for worst case conditions. 


\section{Results and discussion}

\subsection{Three-legged substructure}

An iterative analysis and design process was conducted where the final model contains 44 joints and 89 members. A Z-type brace is used to reduce the number of members and weight of the substruc- ture. The can sections are used in connection joints to increase the punching shear capacity and fatigue life of the structure. The three types of foundations based on installation methods are compared in Table 7.
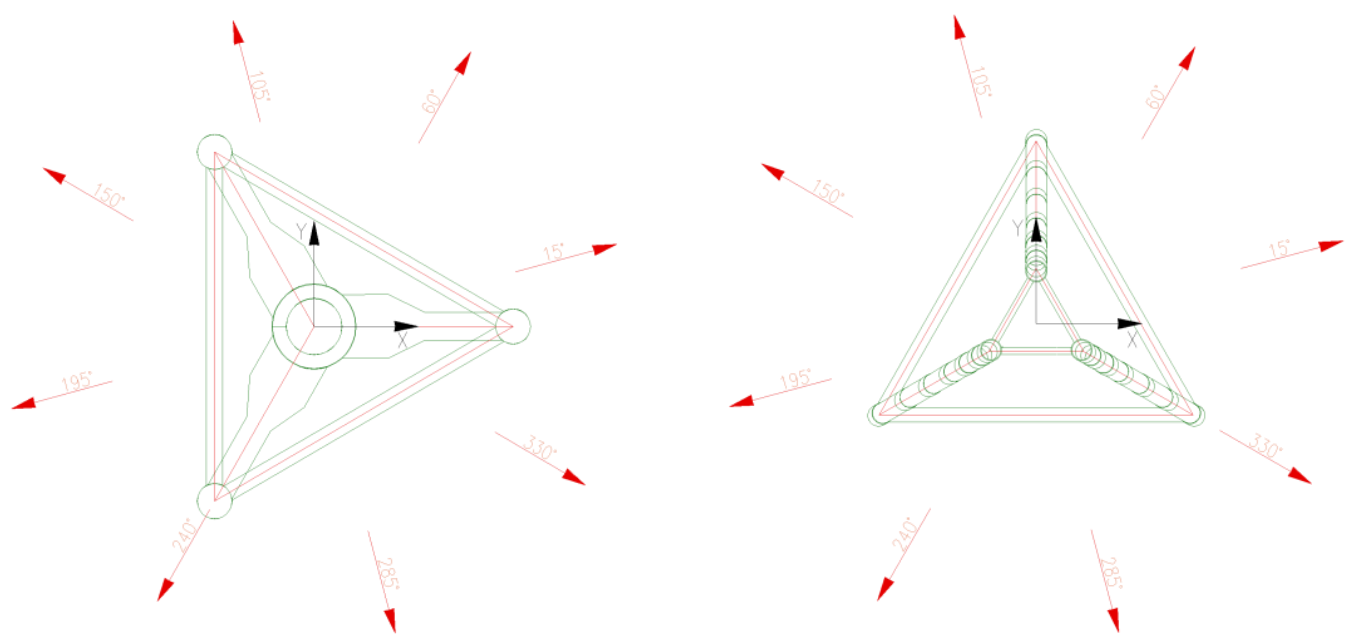

Fig. 7: Direction of environmental loads for tripod and three-legged substructures.

Table 7: Comparison of three types of foundations for three-legged substructures

\begin{tabular}{|c|c|c|c|c|}
\hline Type of Foundation & & $\begin{array}{l}\text { Wishbone } \\
\text { (post-piling) }\end{array}$ & $\begin{array}{c}\text { Grouted Pile* } \\
\text { (post-piling) }\end{array}$ & Pre-piling \\
\hline Weight of Substructure & [tonne] & 486.12 & 400.65 & 474.54 \\
\hline Weight of transition Piece & [tonne] & 230 & 230 & 230 \\
\hline Weight of Tower & [tonne] & 212 & 212 & 212 \\
\hline Weight of Piles & [tonne] & 436.98 & 446.51 & 291.06 \\
\hline Total Weight & [tonne] & 1365.1 & 1289.16 & 1207.6 \\
\hline Pile Size & {$[\mathrm{mm}]$} & 1667x 40(Avg.) & 1372x 40(Avg.) & 2000x40(Avg.) \\
\hline Pile length inside leg & {$[\mathrm{m}]$} & 61.3 & 61.3 & - \\
\hline Dimension of each triangle row $(\mathrm{El} .+8.0)$ & {$[\mathrm{m}]$} & 10.5 & 10.5 & 10.5 \\
\hline Dimension of each triangle row(El.-50.0) & {$[\mathrm{m}]$} & 22 & 22 & 22 \\
\hline Legs max. unity check & {$[-]$} & 0.88 & 0.52 & 0.76 \\
\hline Diagonal braces max. unity check & {$[-]$} & 0.76 & 0.86 & 0.71 \\
\hline Horizontal braces max. unity check & {$[-]$} & 0.74 & 0.82 & 0.62 \\
\hline Natural frequency(1st Mode) & {$[\mathrm{Hz}]$} & 0.267 & 0.265 & 0.268 \\
\hline
\end{tabular}

$*=$ The grout between piles and legs is not considered in structural weight.

The results presented in Table7 show that pre-piling has lesser weight compared to the other two types. This may be explained as; in the pre-piling method the piles are no longer inserted into the legs. Therefore, the weight of piles reduces significantly (33\% and $35 \%$ in wishbone type and grouted pile, respectively). However, the diameter of the piles will increase. The installation method of the substructure should be taken into consideration. Pre-piling method has more advantages than post-piling as mentioned earlier. The final three-legged model members sizes are shown in Figure 8. The first and second modes for dynamic analysis are shown in Figure 9.

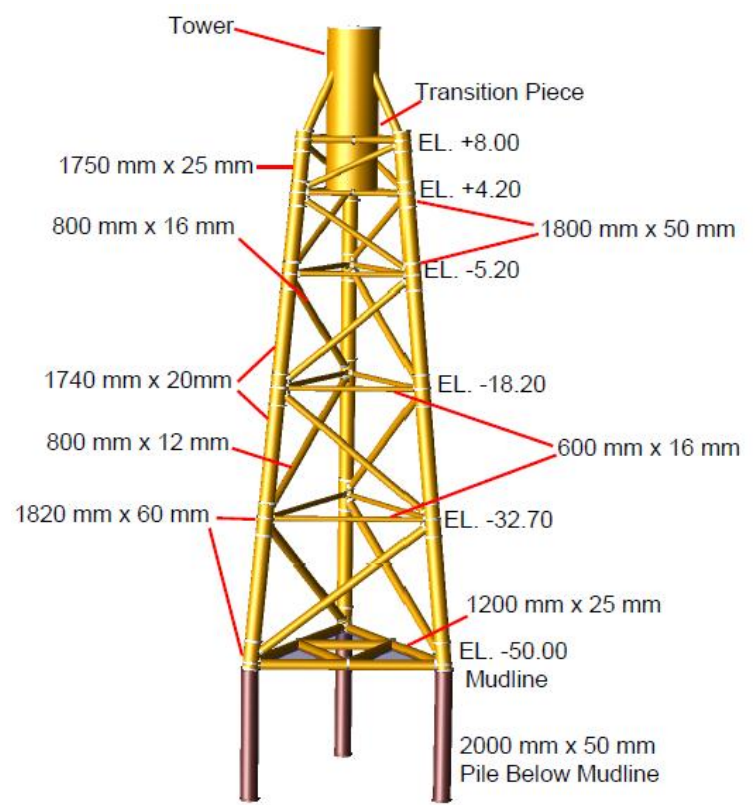

Fig. 8: Three-legged members sizes. 


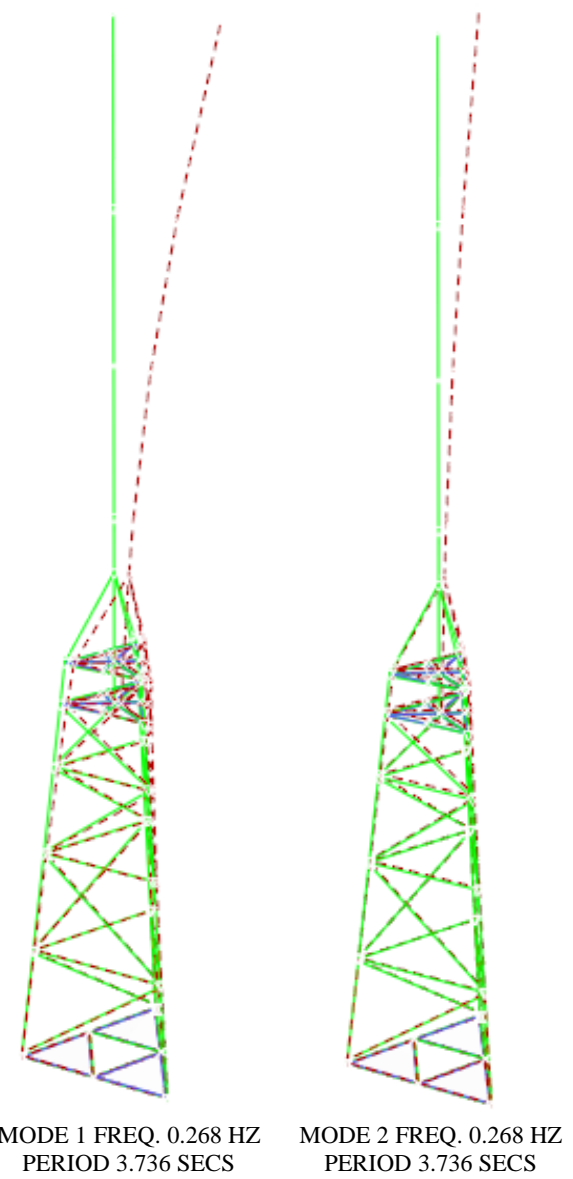

Fig. 9: The first and second mode shape of Three-legged substructure.

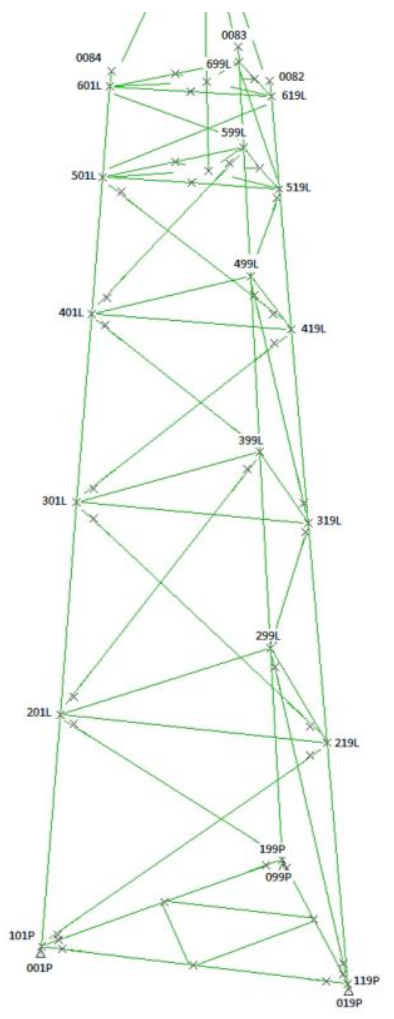

Fig. 10 Three-legged substructure main joints labels.

A summary of the fatigue analysis results of the three-legged substructure joints is presented in Table 8 for the Joints labelled and depicted in Figure 10. The transfer functions, base shear in $15^{\circ}$ and overturning moment in $15^{\circ}$, are shown in Figures 11 and 12 , respectively

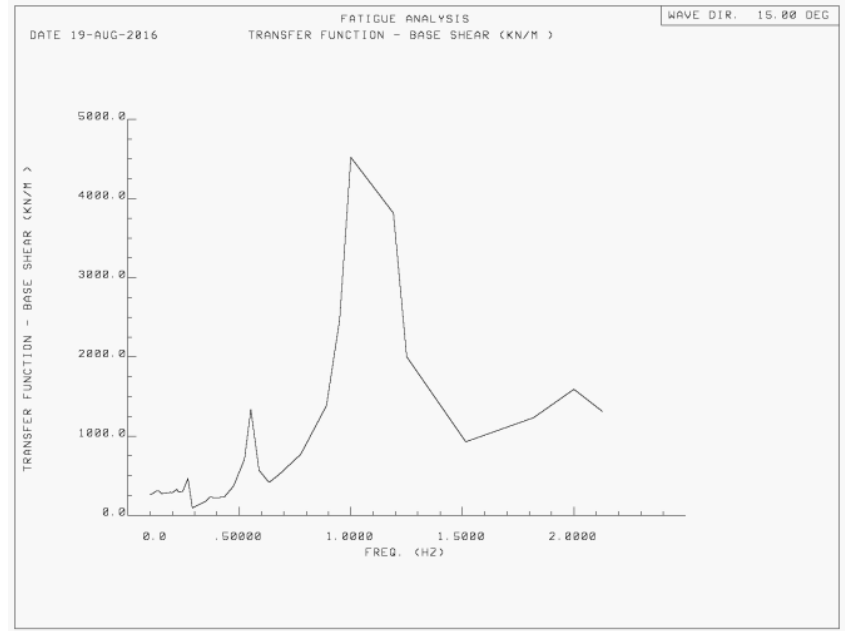

Fig. 11: The transfer function - Base shear in $15^{\circ}$.

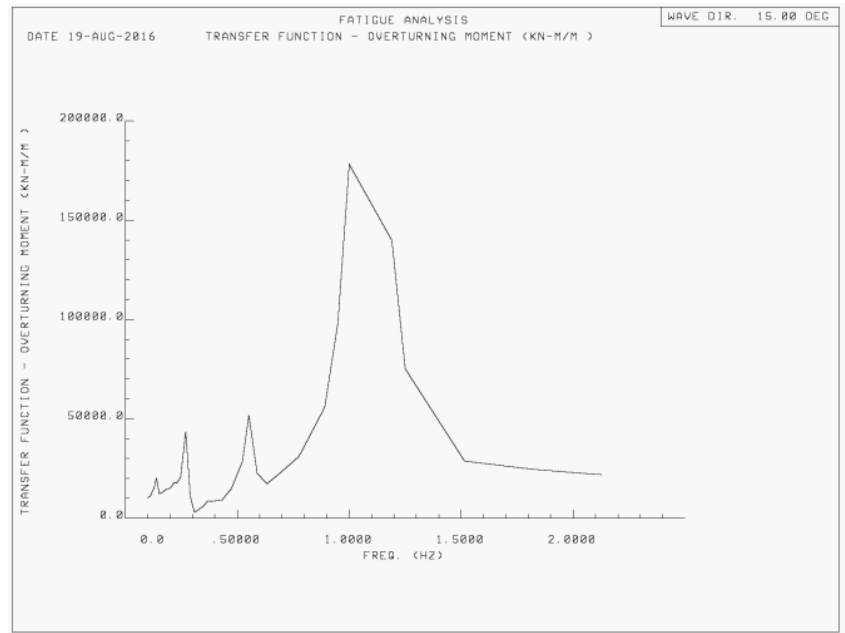

Fig. 12: The transfer function - Overturning Moment in $15^{\circ}$.

Table 8: Three-legged main joints fatigue life results

\begin{tabular}{lccc}
\hline \multirow{2}{*}{ Joint } & \multirow{2}{*}{ Location } & \multicolumn{2}{c}{ Fatigue Service Life } \\
\cline { 3 - 4 } & & safety factor 2 & safety factor 3 \\
\hline 699L & Joint at El. +8.00 & 122.01 & \\
519L & Joint at El. +4.20 & 38.69 & $21.79 *$ \\
419L & Joint at El. -5.20 & - & \\
319L & Joint at El. -18.20 & 27.36 & \\
299L & Joint at El. -32.70 & 29.82 & \\
101P & Joint at El. -50.00 & 137.16 & \\
\hline & $*$ & The safety factor 3 is considered for splash zone
\end{tabular}

\subsection{Tripod substructure}

As in the three-legged substructure, as iterative analysis and design process was conducted where the final model of tripod substructure contains 82 joints and 73 members. The can sections are used in connection joints in order to increase punching shear capacity and fatigue life of structure. In addition to pre-piling and post-piling for foundations are investigated and the results were compared. Table 9 shows that the pre-piling method has less structural mass compared to the post-piling method. However, the difference in general is not significant. The final tripod members details are shown in Figure 13. The first and second modes for dynamic analysis are shown in Figure 14 


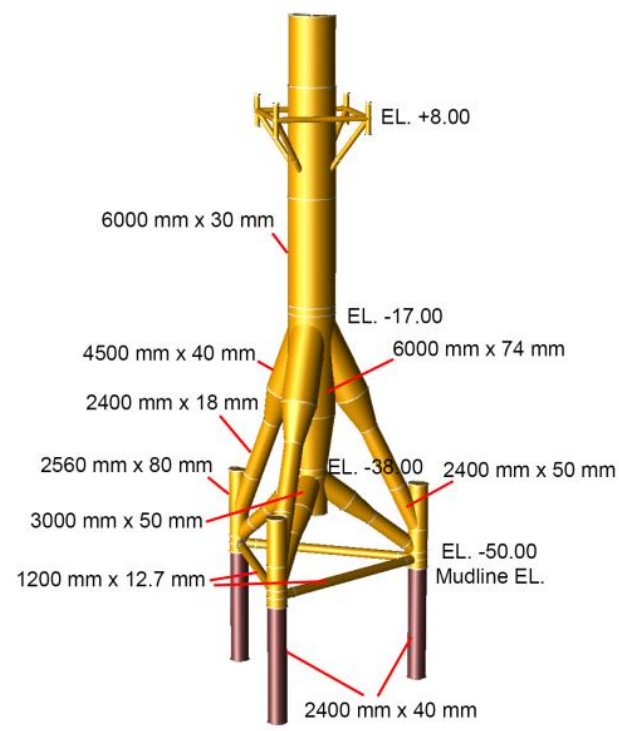

Fig. 13: Tripod members details.

A summary of the fatigue analysis results of the tripod substructures joints are presented in Table 10 where the joints are labelled and depicted in Figure 15. The transfer functions, base shear in $15^{\circ}$ and overturning moment in $15^{\circ}$, are shown in Figures 16 and 17, respectively.

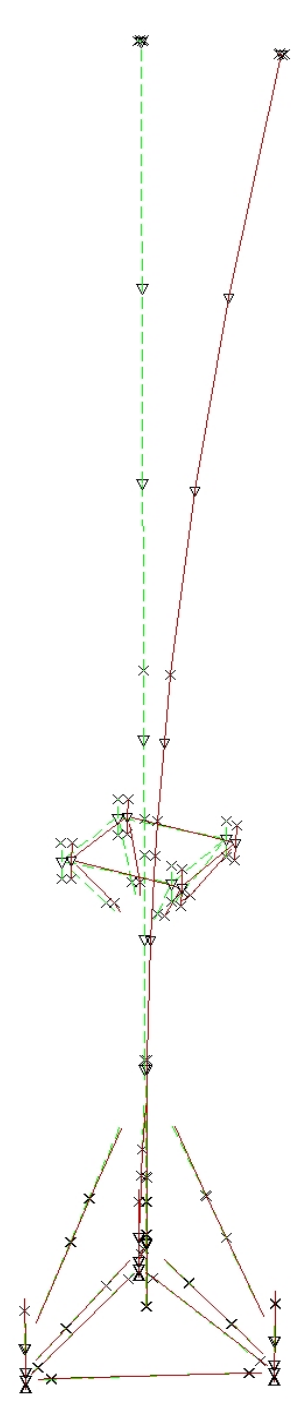

MODE 1 FREQ. 0.235 HZ

PERIOD 4.252 SECS

Fig. 14: The first and second mode shape of tripod substructure.
Table 9: Comparison of two types of foundations for tripod

\begin{tabular}{lcc}
\hline Type of Foundation & Post-Piling & Pre-piling \\
\hline Weight of Substructure [tonne] & 678.08 & 716.11 \\
Weight of transition Piece [tonne] & 230 & 230 \\
Weight of Tower [tonne] & 212 & 212 \\
Weight of Piles [tonne] & 391.5 & 308.4 \\
Total Weight [tonne] & 1511.58 & 1466.51 \\
Pile Size [mm] & $2400 \times 40$ & $2400 \times 40$ \\
Pile length inside leg [m] & 12 & - \\
Pile length under seabed [m] & 50 & 50 \\
Dimension of each triangle row & 24.5 & 24.5 \\
(El.-50.0) [m] & 0.225 & 0.226 \\
Natural frequency(1st Mode) [Hz] &
\end{tabular}

$*=$ The grout between piles and legs is not considered in structural weight
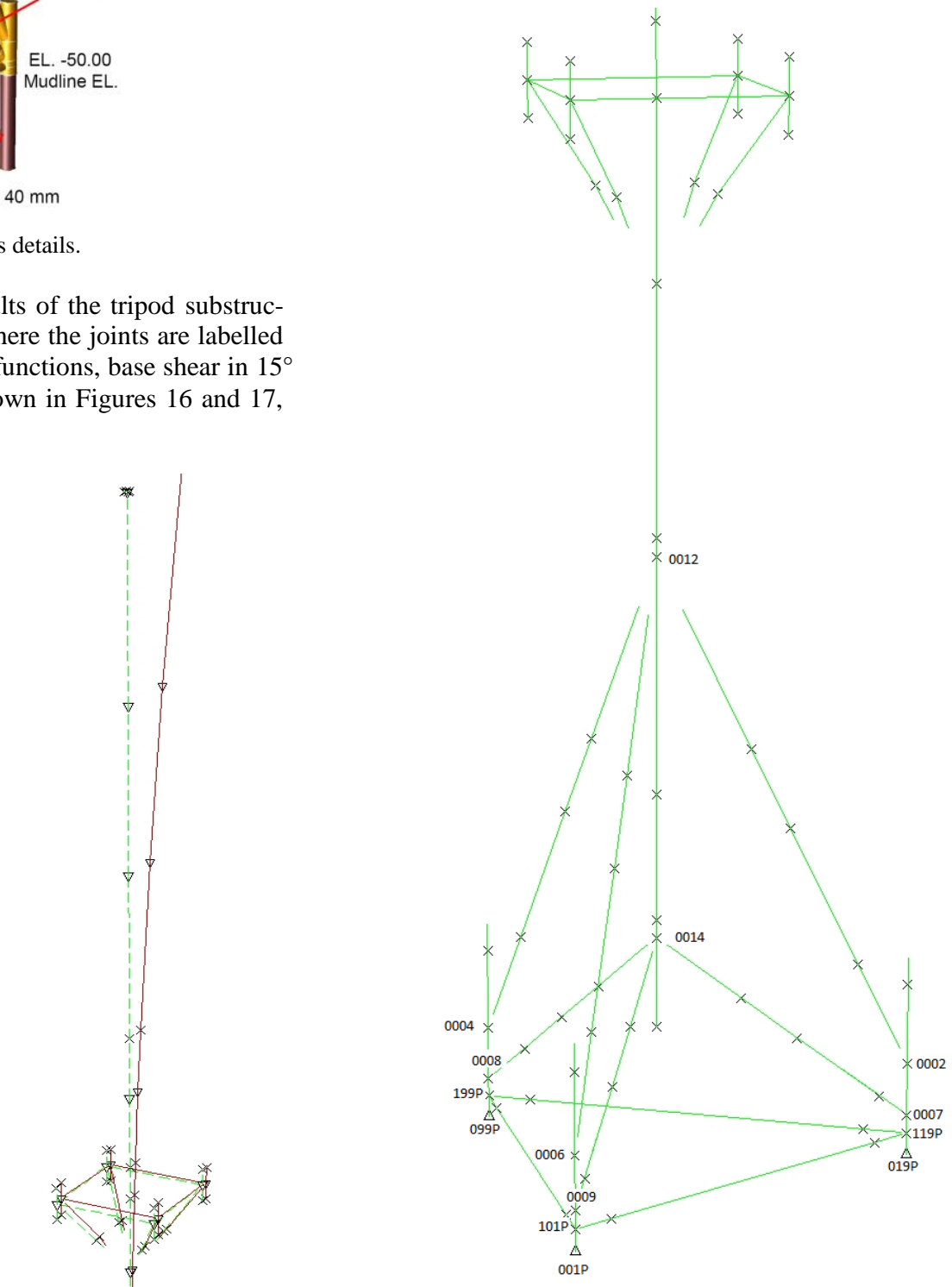

Fig. 15 Tripod substructure main joints label.

Table 10: Tripod main joints fatigue life results

\begin{tabular}{cccc}
\hline \multirow{2}{*}{ Joint } & \multirow{2}{*}{ Location } & \multicolumn{2}{c}{ Fatigue Service Life } \\
\cline { 3 - 4 } & & safety factor 2 & safety factor 3 \\
\hline 12 & Main Joint (El. -17.0 m) & 22.51 & - \\
14 & Middle Joint (El. -38.0 m) & 21.70 & - \\
$119 \mathrm{P}$ & Bottom Joint (El. -50.0 m) & 29.80 & - \\
\hline
\end{tabular}




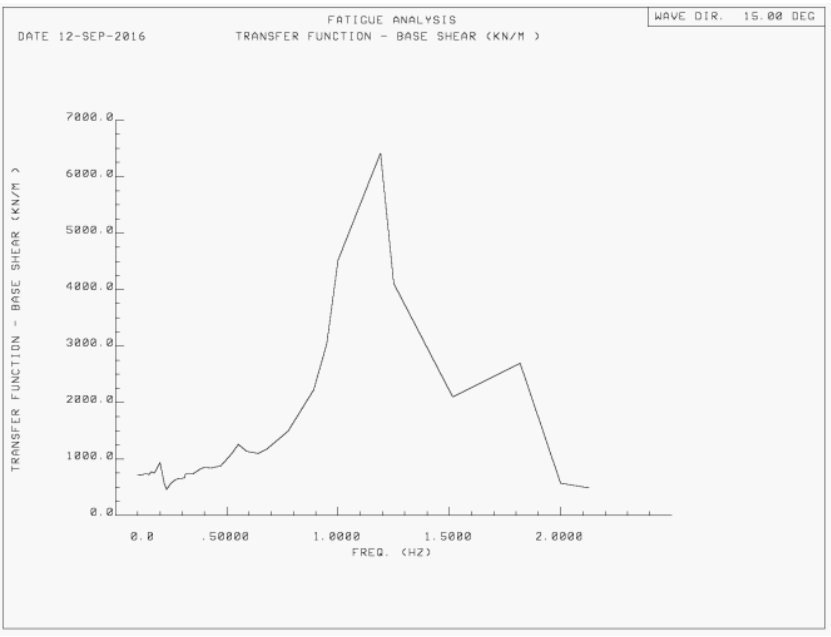

Fig. 16: The transfer function - Base shear in $15^{\circ}$.

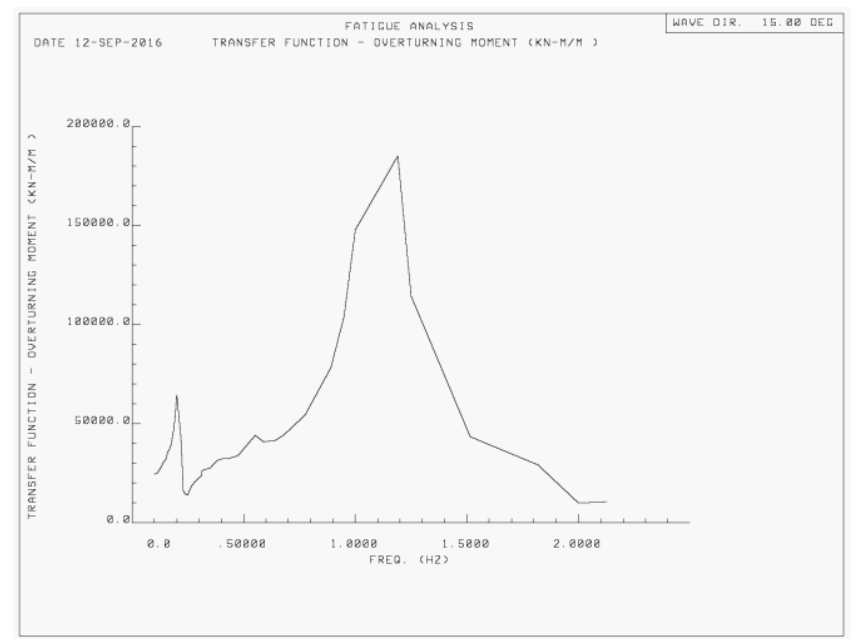

Fig. 17: The transfer function - Overturning moment in $15^{\circ}$.

\section{Conclusion}

This study aimed at investigating three-legged and tripod offshore wind turbine substructures. A comparison between the two substructures based on the weight of substructures as well as the installation method of piles was carried out. The results revealed that the three-legged concept is a feasible and interesting alternative rather than the tripod concept in the chosen site and for similar sites in the transition water depth. The three-legged substructure has less critical joints in terms of fatigue analysis. Besides, the three-legged is potentially more cost-effective, with a $25 \%$ reduction of structural mass. The construction skills required are widely available mainly in oil and gas industry. However, the construction of the three-legged sub-structure will take more time due to an increased number of members and welding joints.

The difficulty in the construction of the tripod substructure is that the column diameter is quite large (around $6 \mathrm{~m}$ ), trolling this size of plate is very complicated due to ovality (deviation from perfect circularity).

The results, furthermore, showed that the pre-piling method in three-legged and tripod substructures reduces the overall weight of piles by $50 \%$ and $27 \%$, respectively. Furthermore, pre-piling operations can be done parallel to the fabrication of substructure thereby expediting the completion of the project with regards to a wind farm which consists of numbers of offshore wind turbines. Up to date, the tripod is employed in many projects worldwide where it is used for shallow water due to fabrication simplicity. It is difficult to say if the three-legged substructure will have an increasing demand in the future, although some developers foresee more wind farms planned with jacket foundations in the next five years. The authors expect an increased demand for the threelegged substructure in deeper waters in the future.

\section{Acknowledgement}

The authors acknowledge the University of Nottingham Malaysia Campus for providing the facilities to carry out the research.

\section{References}

[1] Arany L, Bhattacharya S, Macdonald J \& Hogan SJ, "Design of monopiles for offshore wind turbines in 10 steps", Soil Dynamics and Earthquake Engineering, Vol. 92, 2017, pp. 126-152.

[2] Kaveh A \& Sabeti S, "Optimal Design of Jacket Supporting Structures for Offshore Wind Turbines Using CBO and ECBO Algorithms", Periodica Polytechnica Civil Engineering, Vol. 62, No. 3, 2018, 10 pp.

[3] Ma L \& Nishino T, "Preliminary estimate of the impact of support structures on the aerodynamic performance of very large wind farms", Journal of Physics: IOP Conf. Series 1037, 2018, 15 pp., doi :10.1088/1742-6596/1037/7/072036

[4] Damiani R, Dykes K \& Scott G, "A comparison study of offshore wind support structures with monopiles and jackets for U.S. waters", Journal of Physics: IOP Conf. Series 753, 2016, 14 pp., doi:10.1088/1742-6596/753/9/092003

[5] Jonkman JM (2007), Dynamics Modeling and Loads Analysis of an Offshore Floating Wind Turbine, Technical Report NREL/TP-50041958, NREL National Renewable Energy Laboratory.

[6] Kolios A, Collu M, Chahardehi, A, Brennan FP \& Patel MH, "A Multi-Criteria Decision Making Method to Compare Support Structures for Offshore Wind Turbines", EWEC2010, Europe's premier wind energy event, Warsaw, 2010, 9 pp.

[7] Ashish CB \& Panneer Selvam R, "Static and Dynamic Analysis of Jacket Substructure for Offshore Fixed Wind Turbines", the Eighth Asia-Pacific Conference on Wind Engineering,, Chennai, India, 2013, pp. 1294-1302.

[8] Chew KH, Ng EYK, Tai K, Muskulus, K \& Zwick D, "A Comparison Study Between Four-Legged and Three-Legged Designs", Journal of Ocean and Wind Energy, The International Society of Offshore and Polar Engineers, Vol. 1 No. 2, 2014, pp. 74-81.

[9] Vitor (2016). Reshadat Oil Field Redevelopment, Persian Gulf, Iran, available at http://www.offshoretechnology.com/projects/reshadat-oil-fieldredevelopment-persiangulf/reshadat-oil-field-redevelopment-persian-gulf1.html

[10] de Vries, W. (2011). Final Report WP 4.2: Support Structure Concepts for Deep Water, Technical Report UpWind Deliverable D4.2.8, Delft University of Technology, Delft, Netherlands, 210 pp.

[11] Bhattacharya S, "Challenges in Design of Foundations for Offshore wind turbines", Engineering \& Technology Reference, The institution of engineering and technology, 2014, pp. 1-9.

[12] Brebbia CA \& Walker S (1979), Dynamic Analysis of Offshore Structures, Butterworths.

[13] Khalifa AA, Aboul Haggag SY \& Fayed, MN, "Fatigue Assessment Analysis of Offshore Structures with Application to an Existing Platform in Suez Gulf, Egypt", World Applied Sciences Journal, Vol. 30 No, 8, 2014, pp. 1000-1019.

[14] Noorzaei J, Bahrom SI, Jaafar MS, Thanoon1 WAM \& Mohammad S, "Simulation of Wave and Current Forces on Template Offshore Structures", Suranaree Journal of Science and Technology, Vol. 12 Issue 3, 2005, pp. 193-210.

[15] Henderson R. \& Camp TR, "Hydrodynamic Loading of Offshore Wind Turbines", European Wind Energy Conference European conference, Wind Energy; Wind energy for the new millennium; Copenhagen, 2001, pp. 561-566.

[16] Chakrabarti SK (2005), Handbook of Offshore Engineering, Elsevier.

[17] Zaaijer, MB, "Comparison of Monopile, Tripod, Suction Bucket and Gravity Base Design for a $6 \mathrm{Mw}$ Turbine", Offshore Wind energy in Mediterranean and Other European Seas, OWEMES, Naples, Italy, 2003.

[18] Abdel Raheem SE, "Nonlinear Response of Fixed Jacket Offshore Platform under Structural and Wave Loads", Coupled Systems Mechanics, Vol. 2 No. 1,2013, pp. 111-126.

[19] Efthymiou, M. and Durkin, S. (1985), "Stress concentration in T/Y and gap/overlap K-joints", in Behaviour of Offshore Structures, 
Elsevier Science Publishers B.V., Amsterdam, The Netherlands, pp. 429-440.

[20] Bentley SACS Version 5.7 (2013), EDI, Soft-ware Manual Version 7.

[21] API 2A - LRFD Reaffirmed (2003), Recommended Practice for Planning, Designing, and Constructing Fixed Offshore PlatformsLoad and Resistance Factor Design, American Petroleum Institute.

[22] API RP 2A - WSD 21st Edition (2000), Recommended Practice for Planning, Designing and Constructing Fixed Offshore Platforms Working Stress Design, American Petroleum Institute

[23] DNV (2011), Fatigue Design of Offshore Steel Structures, Recommended Practice DNV-RP-C203, Det Norske Veritas AS, $176 \mathrm{pp}$.

[24] DNV (2014). Design of Offshore Wind Turbine Structures, Offshore Standard DNV-OS-J101, DET Norske Veritas AS, 238 pp.

[25] ISO (2007), Petroleum and natural gas industries - Fixed steel offshore structures, ISO 19902, International Organization for Standardization. 